OPEN ACCESS

Edited by:

Taku Fujimura,

Tohoku University, Japan

Reviewed by:

Kazuyasu Fujii,

Kagoshima University, Japan

Takatoshi Shimauchi,

Hamamatsu University School of

Medicine, Japan

*Correspondence:

Tomomitsu Miyagak

asahikari1979@gmail.com

Specialty section:

This article was submitted to

Dermatology,

a section of the journal

Frontiers in Medicine

Received: 16 April 2019

Accepted: 10 May 2019

Published: 29 May 2019

Citation:

Oka T and Miyagaki T (2019) Novel and Future Therapeutic Drugs for

Advanced Mycosis Fungoides and Sézary Syndrome. Front. Med. 6:116.

doi: 10.3389/fmed.2019.00116

\section{Novel and Future Therapeutic Drugs for Advanced Mycosis Fungoides and Sézary Syndrome}

\author{
Tomonori Oka and Tomomitsu Miyagaki ${ }^{\star}$ \\ Department of Dermatology, Graduate School of Medicine, The University of Tokyo, Tokyo, Japan
}

Mycosis fungoides (MF) and Sézary syndrome (SS) are the most common subtypes of cutaneous T-cell lymphoma. The majority of MF cases present with only patches and plaques and the lesions are usually limited to the skin. On the other hand, in some cases, patients show skin tumors or erythroderma followed by lymph node involvement and rarely visceral organ involvement. SS is a rare, aggressive cutaneous T-cell lymphoma marked by exfoliative erythroderma, lymphadenopathy, and leukemic blood involvement. Because patients with relapsed or refractory MF/SS display a poor prognosis and the current treatment options are characterized by high rates of relapse, there is unmet need for the efficient treatment. This review provides a discussion of the recent and future promising therapeutic approaches in the management of advanced MF/SS. These include mogamulizumab, brentuximab vedotin, alemtuzumab, immune checkpoint inhibitors, IPH4102 (anti-KIR3DL2 antibody), histone deacetylase inhibitors (vorinostat, romidepsin, panobinostat, belinostat, and resminostat), pralatrexate, forodesine, denileukin diftitox, duvelisib, lenalidomide, and everolimus.

Keywords: mycosis fungoides, Sézary syndrome, peripheral T-cell lymphoma, clinical trial, novel therapeutic agents

\section{INTRODUCTION}

Cutaneous T-cell lymphoma (CTCL) comprises a clinically/pathologically heterogeneous group of uncommon non-Hodgkin's lymphomas that manifest primarily in the skin. Mycosis fungoides (MF) is the most common CTCL subtype that accounts for around 60\% of CTCL (1). MF is generally an indolent lymphoma with slow progression over years or even decades. Typically, the initial lesions in MF are flat and erythematous skin patches, which evolve over a variable period of time into palpable plaques characterized by well-demarcated edges. In limited cases, plaques can be followed by tumors and those patients have patch, plaque, and tumor lesions simultaneously on different parts of the body. In some cases, skin lesions develop into erythroderma similar to Sézary syndrome (SS). In MF cases with tumors or erythroderma (advanced MF), lymph node or visceral involvement is sometimes observed and such cases present a poor prognosis. SS is a much rarer variant, accounting for only $3 \%$ of CTCL (1). Characteristics of SS are generalized erythroderma (defined as affecting $>80 \%$ of total body surface area), lymphadenopathy, and presence of circulating tumor cells in the blood. Progression of SS is usually more rapid compared to that of MF. 
Although MF and SS are classified as distinct, separate entities, the same clinical staging system and therapeutic approaches have been used $(1,2)$. Patients with MF having limited T1 stage (limited patches, papules, and/or plaques covering $<10 \%$ of the skin surface) have a similar life expectancy to that of control populations (3). In addition, patients with early stage MF (stage I and IIA) have a good prognosis (a median survival: 15.8 years or more), while patients with advanced stage MF/SS (stage IIB or more) have a poor prognosis (a median survival: 4.7 years or less) (3). Current treatment consists of skin-directed therapies, such as topical corticosteroid, topical mechlorethamine, topical bexarotene, ultraviolet phototherapy, total skin electron beam therapy, and localized radiotherapy (2), for early stage disease and systemic therapies for advanced stage. For early stage MF confined to the skin, therapeutic concept is to control symptoms by skin-directed therapies with the lowest possible therapyrelated side effects, as durable remissions cannot be achieved by early aggressive chemotherapy (4). For advanced stages of MF and SS, there is a variety of systemic therapies available, some of which are used from decades ago and some recently. However, currently available drug therapies are not curative treatment and the only option for curing MF/SS is stem cell transplantation (5).

As MS/SS have the chronic and recurrent nature, repeated treatment courses and maintenance regimens are necessary for disease control. Although there are available active systemic therapeutic strategies, including cytotoxic chemotherapy and biological therapy, better treatments of advanced stage and refractory MF/SS are desired by both patients and physicians. Purpose of the present paper is to review the clinical results obtained in clinical trials of novel currently used and future promising therapies for advanced MF/SS patients (Table 1).

\section{MOGAMULIZUMAB}

C-C chemokine receptor 4 (CCR4) is the receptor for thymus and activation-regulated chemokine and macrophage-derived chemokine and is involved in skin trafficking of type 2 helper $\mathrm{T}$ cells and regulatory $\mathrm{T}$ cells. CCR4 is also consistently expressed on the surface of tumor cells in T-cell malignancies, such as CTCL, including MF and SS, adult T-cell leukemialymphoma, and peripheral T-cell lymphoma (PTCL) (30-33). Mogamulizumab is a humanized IgG1 $\kappa$ monoclonal antibody with a defucosylated Fc region, which selectively binds to CCR4. The antibody exerts its antitumor activity by antibodydependent cellular cytotoxicity (34). First, mogamulizumab has been approved in Japan for relapsed or refractory CCR $4^{+}$adult

\footnotetext{
Abbreviations: CTCL, cutaneous T-cell lymphoma; PTCL, peripheral T-cell lymphoma; MF, mycosis fungoides; SS, Sézary syndrome; ALCL, anaplastic large cell lymphoma; $\mathrm{AE}$, adverse event; ORR, overall response rate; $\mathrm{CR}$, complete response; $\mathrm{PR}$, partial response; $\mathrm{SD}$, stable disease; $\mathrm{PFS}$, progression free survival; OS, overall survival; DOR, duration of response; CCR4, C-C chemokine receptor 4; HDAC, histone deacetylase; PNP, purine nucleoside phosphorylase; MMAE, monomethyl auristatin E; IL-2R, IL-2 receptor; PI3K, Phosphoinositide-3-kinase; FDA, Food and Drug Administration; EMA, European Medicines Agency; CTLA4, cytotoxic $\mathrm{T}$ lymphocyte-associated protein 4; $\mathrm{PD}-1$, programmed cell death protein 1 ; mTOR, mammalian target of rapamycin.
}

T-cell leukemia-lymphoma (2012), PTCL (2014), and CTCL (2014) (35).

Before the approval of mogamulizumab in Japan, seven patients with MF had been enrolled in a multicenter phase 2 study for patients with relapsed PTCL and CTCL in Japan (6). Intravenous infusions of $1.0 \mathrm{mg} / \mathrm{kg}$ mogamulizumab were administered to patients once per week for 8 weeks. The overall response rate (ORR) for MF patients was 28.6\% [all partial response (PR) with no complete response (CR)]. A phase 1/2 study was also conducted for 38 patients with pretreated CTCL (MF and SS) in USA. Mogamulizumab was administered once weekly for 4 weeks using an escalation scheme $(0.1 \mathrm{mg} / \mathrm{kg}$ and subsequent doses of 0.3 and $1.0 \mathrm{mg} / \mathrm{kg}$ ) followed by $1.0 \mathrm{mg} / \mathrm{kg}$ every 2 weeks until disease progression or withdrawal. The ORR was 36.8\% (CR 7.9\% and PR 28.9\%). Mogamulizumab was more effective for patients with SS than those with MF; ORR was $47.1 \%$ in SS $(n=17)$ and $28.6 \%$ in MF $(n=21)$. Eighteen of $19(94.7 \%)$ patients with blood involvement had a response in blood, including $11 \mathrm{CRs}$ (7). In an international, open-label, randomized, controlled phase 3 trial in patients with relapsed or refractory MF/SS (MAVORIC study), mogamulizumab (1.0 $\mathrm{mg} / \mathrm{kg}$ once weekly for 4 weeks followed by every 2 weeks) significantly showed the high ORR and prolonged progression free survival (PFS) compared with $400 \mathrm{mg} /$ day vorinostat (8). The ORR of mogamulizumab was $28 \%$ (21\% in MF and $37 \%$ in SS), while the ORR of vorinostat was $4 \%$ (8). The median PFS was 7.7 months for the mogamulizumab group, compared with 3.1 months for vorinostat. Compartment response rates were $78 / 186(42 \%)$ in skin, $83 / 122(68 \%)$ in blood, $21 / 124$ (17\%) in lymph nodes, and $0 / 3(0 \%)$ in viscera, suggesting that mogamulizumab is effective especially for blood involvement. In all studies, mogamulizumab showed an acceptable safety profile and common toxicities included nausea, chills, headache, fever, diarrhea, pruritus, and infusion reactions. Based on these results, mogamulizumab was approved for the treatment of patients with CTCL who have received at least 1 prior systemic therapy by the US Food and Drug Administration (FDA) and European Medicines Agency (EMA) in 2018.

\section{BRENTUXIMAB VEDOTIN}

CD30 is a cell membrane protein that belongs to the tumor necrosis factor receptor family. CD30 was originally discovered on Reed-Sternberg cells of Hodgkin's lymphoma, and its expression was subsequently demonstrated on subsets of nonHodgkin lymphoproliferative disorders, notably systemic, and primary cutaneous anaplastic large T-cell lymphoma (ALCL) and lymphomatoid papulosis. CD30 is also expressed on tumor cells of some MF/SS cases at various levels, and cases with large cell transformation frequently show higher expression. Brentuximab vedotin $(\mathrm{BV})$ is an antibody-drug conjugate composed of the cytotoxic antitubulin agent monomethyl auristatin E (MMAE) and a chimeric monoclonal anti-CD30 antibody (36). After BV binds to CD30, the antibody-drug conjugate is internalized, and the antibody is cleaved by the lysosome, leading to the intracellular release of MMAE (37). MMAE inhibits tubulin 
TABLE 1 | Summary of the results of clinical trials of single-agents in cutaneous T-cell lymphoma or peripheral T-cell lymphoma including a given number of mycosis fungoides or Sézary syndrome patients.

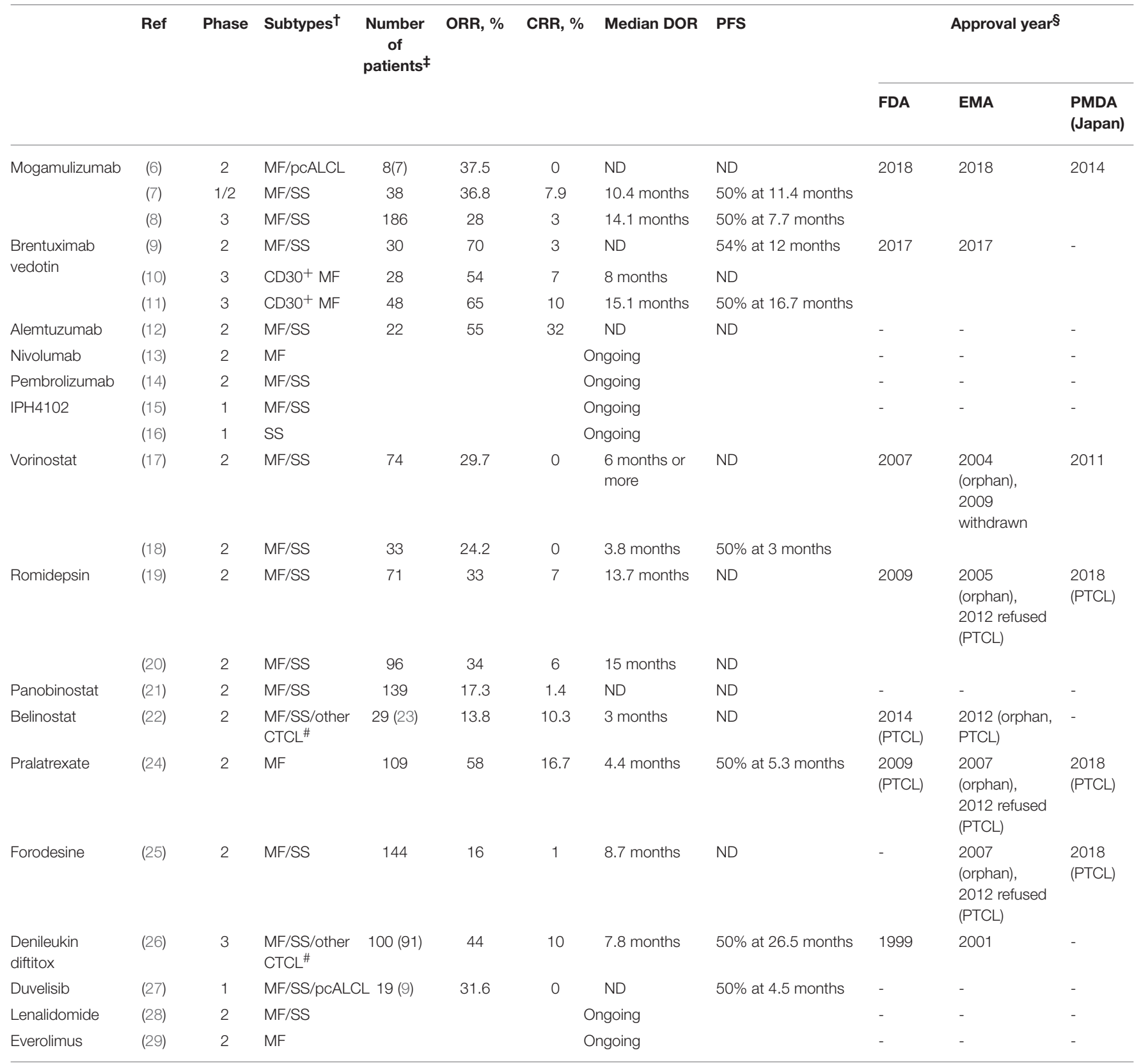

${ }^{\dagger}$ When data regarding patients with MF/SS is separable in the original paper, data on MF/SS patients is shown. When inseparable, data on CTCL patients is shown.

${ }^{\ddagger}$ When data regarding patients with MF/SS is inseparable in the original paper, the number of patients with MF/SS is shown in parentheses.

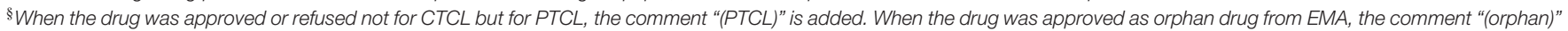
is added.

\# Other CTCL includes pCALCL, peripheral T-cell lymphoma, not otherwise specified, and subcutaneous panniculitis-like T-cell lymphoma.

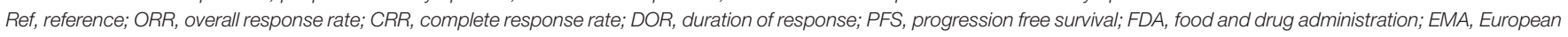

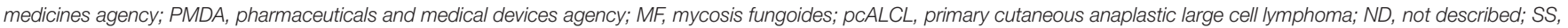
Sézary syndrome; PTCL, peripheral T-cell lymphoma; CTCL, cutaneous T-cell lymphoma.

polymerization and consequently disrupts the microtubule network within the cells causing cell cycle arrest and apoptosis. In addition, a small fraction of MMAE is released from CD30 ${ }^{+}$ cells, killing neighboring cells in the tumor microenvironment in a CD30-independent manner $(36,37)$. BV has received regulatory approval in more than 65 countries for the treatment of relapsed or refractory Hodgkin's lymphoma and systemic ALCL (38). 
The results of two phase 2 studies of $\mathrm{BV}$ for $\mathrm{CD} 30^{+} \mathrm{CTCL}$ including MF/SS were reported in 2015. In one phase 2 trial of 30 evaluable patients with pretreated $\mathrm{CD} 30^{+} \mathrm{MF} / \mathrm{SS}$ by Kim et al, the patients received up to 16 cycles of BV $(1.8 \mathrm{mg} / \mathrm{kg})$ every 3 weeks. The ORR was observed in $21(70 \%)$ of 30 patients (CR in one patient and $\mathrm{PR}$ in 20 patients), and patients with CD30 expression $<5 \%$ exhibited a decreased probability of response compared with patients with CD30 expression $>5 \%$. (9). In the other trial of BV for 48 pretreated patients with primary cutaneous $\mathrm{CD}^{+}{ }^{+}$lymphoproliferative disorders, 28 patients with $\mathrm{CD} 30^{+}$ MF were included (10). BV was administered intravenously at $1.8 \mathrm{mg} / \mathrm{kg}$ every 3 weeks for a maximum of eight doses. The ORR in MF patients was $54 \%$ with CR in two cases and the response was independent of CD30 expression. Based on these promising results, the international randomized phase 3 trial (ALCANZA study) for pretreated CD $30^{+}$CTCL (MF or primary cutaneous ALCL) had been conducted recently to compare BV against the chosen standard therapy by physicians (methotrexate or bexarotene). In this clinical trial, included cases expressed the CD30 molecule on at least $10 \%$ of the skin infiltrate BV (1.8 $\mathrm{mg} / \mathrm{kg}$ every 3 weeks) and methotrexate (5-50 mg weekly) or bexarotene $\left(300 \mathrm{mg} / \mathrm{m}^{2}\right.$ daily) were administered until disease progression or the development of major toxicity. Among the enrolled patients, 97 patients with MF were included. Forty-eight patients were treated with BV and the remaining 49 patients were treated with methotrexate or bexarotene. The ORR lasting at least 4 months was increased in the BV cohort compared with the physician's choice cohort (50 vs. 10\%). Five patients achieved CR with $\mathrm{BV}$, while methotrexate or bexarotene failed to achieve $\mathrm{CR}$ in any patient. After a median follow-up time of 17.5 months, the median PFS was 15.9 months for patients in the BV cohort and 3.5 months for patients in the methotrexate or bexarotene cohort (11). Peripheral neuropathy was the most frequent adverse event (AE) and was observed in $67 \%$ of patients undergoing treatment with BV. After a median 22.9 months of follow-up, 82\% of patients with peripheral neuropathy experienced improvement or resolution. Other common side effects reported during the study included nausea, diarrhea, vomiting, alopecia, itching, fever, and loss of appetite. These data suggested that BV can be a preferable treatment option for the treatment of MF when biopsy samples have $10 \%$ or more $\mathrm{CD} 30^{+}$malignant cells. In 2017, FDA and EMA approved BV for the treatment of adult patients with $\mathrm{CD}^{+} 0^{+} \mathrm{MF}$ who have received prior systemic therapy.

\section{ALEMTUZUMAB}

CD52 is a small glycopeptide composed of 12 aminoacids expressed on the cell surface of several different types of leukocytes, including normal and malignant $\mathrm{T}$ lymphocytes. Alemtuzumab is a humanized IgG1 antibody that targets the CD52 antigen. The phase 2 study of alemtuzumab in patients with advanced MF/SS who did not respond adequately to treatment with at least PUVA, radiotherapy, or chemotherapy, showed that the ORR was 55\% with $32 \%$ CR and $23 \%$ PR (12). The effect was better on erythrodermic patients $(69 \%$ ORR with $38 \% \mathrm{CR}$ ) than on patients with plaques or tumors
(40\% ORR with $30 \% \mathrm{CR}$ ). In that study, alemtuzumab was administered using escalating doses $(5,10,30 \mathrm{mg}$ intravenously on days 1-3) and then $30 \mathrm{mg}$ /day three times a week for up to 12 weeks. Because AEs of alemtuzumab such as infusion reaction, hematologic toxicity, and infectious complications were severe, clinical trials of low-dose alemtuzumab were performed for CTCL. In 14 patients with SS treated with subcutaneous lowdose alemtuzumab ( $3 \mathrm{mg}$ on day 1, $10 \mathrm{mg}$ on day 3 , then $15 \mathrm{mg}$ on alternating days or $3 \mathrm{mg}$ on day 1 , then $10 \mathrm{mg}$ on alternating days), the ORR was $85.7 \%$ with $21.4 \%$ CR and $64.3 \%$ PR (39). Infectious episodes were observed only in patients treated with $15 \mathrm{mg}$ alemtuzumab. These studies suggest that low-dose alemtuzumab can be an effective treatment for erythrodermic MF/SS with acceptable safety. Consistently, a recent report on 23 patients with leukemic involvement treated with lowdose alemtuzumab ( $10 \mathrm{mg}$ subcutaneously, three times a week) described that 13 of 17 patients presented with erythroderma showed CR and that the remaining 4 patients could be controlled by following skin-directed therapy alone. In contrast, CR was not achieved in any patient with discrete patches, plaques, or tumors (40).

\section{IMMUNE CHECKPOINT INHIBITORS}

Immune checkpoint molecules, such as cytotoxic T lymphocyteassociated protein 4 (CTLA-4) and programmed cell death protein 1 (PD-1), act as negative regulators that inhibit normal $\mathrm{T}$-cell responses to avoid the emergence of pathological self-reactivity. On the other hand, cancers occasionally have the capacity to avoid anti-tumor immunity by abusing such immune checkpoint molecules. Thus, immune checkpoint inhibitors can antagonize the immunosuppressive interaction between the tumor cells and $\mathrm{T}$ cells and improve antitumor immune T-cell responses. In recent years, the efficacy of immune checkpoint inhibitors blocking the CTLA-4 and PD1 pathways has been confirmed by several clinical trials in a variety of cancers. PD-1-blocking antibodies (nivolumab and pembrolizumab) and CTLA-4-blocking antibody (ipilimumab) achieved durable objective responses and improved OS in patients with solid tumors $(23,41-44)$ and hematologic malignancies, including Hodgkin's lymphoma (45). Concerning hematological malignancies, in 2016, nivolumab was approved for the treatment of patients with classical Hodgkin lymphoma that has relapsed or progressed after autologous hematopoietic stem cell transplantation and the following post-transplantation BV by FDA. Subsequently, FDA approved pembrolizumab for the treatment of refractory primary mediastinal large B-cell lymphoma patients in 2018.

Current data suggest that the PD-1, PD-L1/PD-L2 pathway may play a significant role in preventing immune-driven eradication of MF/SS tumor cells. Expression of PD-1 and PD-L1 has been detected in tumor cells of various morphological subsets of MF (46) as well as tumor cells circulating in the peripheral blood of SS (47). A recent phase $1 \mathrm{~b}$ study of nivolumab in 81 patients with relapsed or refractory hematologic malignancy included 13 patients with MF. The ORR in MF patients was 
15\% (all PR) with 59\% stable disease (SD) and the median PFS was 10 weeks (13). Khodadoust et al. presented preliminary data from a multicenter phase 2 open label study of pembrolizumab in 24 advanced and refractory CTCL patients (9 MF, 15 SS) (14). The ORR was $37.5 \%$ with $1 \mathrm{CR}, 8 \mathrm{PR}$, and $9 \mathrm{SD}$, and the median PFS has not yet been reached. Of the 9 responding patients, 6 patients had $90 \%$ or greater decrease in modified Severity Weighted Assessment Tool score. Treatment was welltolerated with a toxicity profile which was consistent with prior studies (48), although a notable skin flare reaction was developed in $40 \%$ of SS patients. Although it is necessary to wait for the results of several ongoing clinical trials using immune checkpoint inhibitors such as nivolumab, ipilimumab, and durvalumab (antiPD-L1 antibody), immune checkpoint inhibition can be a novel strategy to treat advanced MF/SS.

\section{IPH4102 (ANTI-KIR3DL2 ANTIBODY)}

KIR3DL2 (CD158k), a member of the highly polymorphic killercell immunoglobulin-like receptor family, has the capacity to bind to MHC class I and transduce an inhibitory signal. KIR3DL2 is expressed on subsets of normal $\mathrm{CD}^{+} \mathrm{T}$ cells and NK cells, but not on normal $\mathrm{CD}^{+}{ }^{+}$cells (49). On the other hand, several studies demonstrated that KIR3DL is expressed by neoplastic $\mathrm{CD}^{+} \mathrm{T}$ cells in SS, advanced MF, and primary cutaneous ALCL (50-54). The relative specific expression of KIR3DL2 on the malignant CTCL cells makes it an ideal therapeutic target. IPH4102 is a humanized, monoclonal antibody specific toward KIR3DL2 which lacks cross-reactivity with other members of the human killer-cell immunoglobulin-like receptor family. IPH4102 selectively and efficiently can deplete KIR3DL2 ${ }^{+}$cells including primary Sézary cells through antibody-dependent cell cytotoxicity and phagocytosis (55).

Preliminary results from the phase 1 study were presented at the 2017 European Organization for Research and Treatment of Cancer: Cutaneous Lymphoma Task Force in London (15). The aim of the trial is to characterize IPH4102 safety profile and identify the maximum tolerated dose and recommended phase 2 dose. A total of 25 patients, including 20 patients with SS, four patients with MF, and one patient with $\mathrm{CD} 4^{+}$CTCL (neither MF nor SS), have been treated at the 10 preplanned ascending dose levels $(0.0001-10 \mathrm{mg} / \mathrm{kg})$. All patients had relapsed after or had been refractory to at least two prior systemic therapies. The ORR was $44 \%$ (1 CR and $10 \mathrm{PR}$ ). Two patients achieved a near CR ( $>90 \%$ reduction in skin involvement). The median duration of response (DOR) was 8.2 months, and the median PFS was 9.8 months. As IPH4102 was safe and well-tolerated in those dose-escalation cohorts, expansion cohorts started at the flat dose of $750 \mathrm{mg}$ in 2017. Preliminary results of expansion cohorts were presented at the 60th American Society of Hematology annual meeting in 2018 (16). The study included 35 SS patients with at least two prior systemic therapies. The ORR was $42.9 \%$ (5.7\% CR and $37.2 \% \mathrm{PR}$ ) with a favorable safety profile. The median DOR was 13.8 months and the median PFS was 11.7 months. Preliminary phase 1 data suggest that IPH4102 is both efficacious and well-tolerated. A global, multi-cohort, phase 2 study evaluating the potential of IPH4102 in different subtypes of T-cell lymphoma will be initiated this year (NCT03902184).

\section{HDAC INHIBITORS}

Histone deacetylase (HDAC) inhibitors have the capacity to increase acetylation of histones and other proteins, which exerts chromatin remodeling, promotion of tumor suppressor gene transcription, and apoptosis, resulting in antitumor activity. Its clinical activity is largely confined to hematologic malignancies, particularly CTCL (56). HDAC inhibitors have the prevalent AEs of fatigue, thrombocytopenia, diarrhea, and nausea in common (57).

Although vorinostat is not a novel drug, we referred to the drug in this paragraph, because it is the first approved HDAC inhibitor. Vorinostat is an oral competitive inhibitor of class I/II HDAC enzymes. In the pivotal phase $2 \mathrm{~B}$ multicenter trial, $400 \mathrm{mg}$ of vorinostat was administered daily to 74 stage IB-IVA MF/SS patients, who were previously treated with two or more prior systemic therapies, until disease progression or intolerable toxicity (17). The ORR was $29.7 \%$ (22/74) and all initial responses were confirmed PR. The other phase 2 clinical trial showed similar results (18). Eight of 33 patients (24.2\%) with refractory MF/SS who had received a median of 5 prior therapies achieved PR. In 2006, FDA approved vorinostat for the treatment of CTCL patients who have progressive, persistent or recurrent disease on or following two systemic therapies. Also in Japan, the drug was approved in 2011 based on the phase 1 clinical trial conducted in Japan (58). In a recent phase 3 randomized study, vorinostat was compared with mogamulizumab in patients with stage IB-IV MF/SS (8). The ORR for the vorinostat was significantly lower than that of mogamulizumab (5 vs. $28 \%$ ).

Romidepsin is a bicyclic peptide that inhibits class I HDAC selectively. Preclinical studies suggest that romidepsin is among the most potent HDAC inhibitors. Two multicenter phase 2 clinical trials of romidepsin for CTCL were conducted before 2010. In one clinical trial, 71 refractory IA-IVB MF/SS patients with a median of four prior treatments were enrolled (19). Some patients received $18 \mathrm{mg} / \mathrm{m}^{2}$ romidepsin on days 1 and 5 of a 21 day cycle and to other patients romidepsin was administered at $14 \mathrm{mg} / \mathrm{m}^{2}$ on days 1,8 , and 15 every 28 days. CR was observed in four patients (5.6\%) and 20 patients achieved PR (28.2\%). The median DOR was 13.7 months. In the other international single-arm, open-label, phase 2 study, 96 patients with IB-IVA $\mathrm{MF} / \mathrm{SS}$ who had received one or more prior systemic therapies (median three), received romidepsin intravenously $14 \mathrm{mg} / \mathrm{m}^{2}$ on days 1,8 , and 15 every 28 days (20). The ORR was $34 \%(33 / 96)$, including 6\% (6/96) CRs and the median DOR was 15.0 months, which were similar to the previous study. Interestingly, in the clinical trial, romidepsin is active in subtypes of CTCL with less favorable outcomes, such as tumor stage and folliculotropic MF. The ORR was $45 \%$ (9/20) in patients with cutaneous tumors and $60 \%(6 / 10)$ in patients with folliculotropic disease involvement (59). Of note, Kim et al. reported that a clinically significant effect on pruritus was confirmed in a large number of patients, even in patients without any objective clinical response (60). In 2009, 
romidepsin was approved for the treatment of CTCL patients by FDA.

Panobinostat is an orally bioavailable pan HDAC inhibitor approved for the treatment of multiple myeloma by FDA in 2015. In a phase 2 study, 139 patients with stage IB-IVA MF/SS who had been pretreated with two or more prior systemic therapies, received $20 \mathrm{mg}$ of oral panobinostat three times every week (21). The 139 patients included 79 bexarotene-exposed patients and 60 bexarotene-naïve patients. The ORR was $17.3 \%$ in all patients $(15.2 \%$ in the bexarotene-exposed group and $20.0 \%$ in the bexarotene-naïve group). One $\mathrm{CR}$ was observed in each group. The median PFS was 4.2 months in the bexaroteneexposed group and 3.7 months in the bexarotene-naïve group. The median DOR was 5.6 months in the bexarotene-exposed group and was not reached at data cutoff in the bexarotenenaïve group.

Belinostat is an intravenous inhibitor of pan HDAC, which was approved for the treatment of relapsed or refractory PTCL by FDA in 2014. In the phase 2 clinical trial of belinostat in patients with relapsed or refractory PTCL and CTCL, 29 patients with CTCL including $17 \mathrm{MF}$ patients and seven SS patients were enrolled. Patients with CTCL had received a median of four prior systemic therapies. Belinostat was administered at $1,000 \mathrm{mg} / \mathrm{m}^{2}$ intravenously for consecutive 5 days of a 21 -day cycle (22). The ORR was $13.8 \%$ (10.3\% CR and 3.4\% PR), and the median DOR was 83 days.

Resminostat is an oral drug which selectively inhibits class I, IIB, and IV HDAC enzymes. A phase 2, multicenter, doubleblind, randomized, placebo-controlled trial is currently ongoing to evaluate whether resminostat can be used as maintenance treatment for MF/SS patients after disease control with other systemic therapies (NCT02953301). Patients will receive either placebo or $600 \mathrm{mg}$ resminostat for consequent 5 days followed by 9 days of rest in a 14-day cycle. This clinical trial will be completed in 2020 .

\section{PRALATREXATE}

Pralatrexate, an anti-neoplastic folate analog, inhibits dihydrofolate reductase, targeting DNA synthesis and resulting in tumor cell death. Pralatrexate has the improved anti-tumor activity compared to methotrexate due to higher affinity for the reduced folate carrier-1 and more selective accumulation in tumor cells.

A phase 2 study of pralatrexate in 109 patients with PTCL including 12 transformed MF patients who progressed following one or more prior systemic therapy (PROPEL study) showed that the ORR was 29\% (32 of 109), including $11 \%$ CR and 18\% PR, with the median DOR of 10.1 months. The median PFS and overall survival (OS) were 3.5 and 14.5 months, respectively (61). Subgroup analysis patients with transformed MF revealed that the ORR was 58\% with the median DOR and PFS were 4.4 and 5.3 months, respectively per investigator assessment (24). Pralatrexate was administered at $30 \mathrm{mg} / \mathrm{m}^{2} /$ week for 6 weeks followed by one week of rest (7-week cycle) in this study. FDA approved pralatrexate for the treatment of PTCL in 2009. In Japan, after phase $1 / 2$ clinical study was conducted, pralatrexate was approved in 2018 (62).

As for CTCL, a dose de-escalation study of pralatrexate showed that the recommended regimen was identified as 15 $\mathrm{mg} / \mathrm{m}^{2} /$ week for 3 weeks followed by 1 week of rest (4-week cycle) (63). Twenty-nine patients with refractory MF/SS and primary cutaneous ALCL with at least one prior systemic therapy received recommended dosing regimen. The ORR was $45 \%$ with $1 \mathrm{CR}$ and $12 \mathrm{PR}$. In any study, the most observed toxicity is mucositis. To reduce this risk, patients received supplementation of vitamin B12 and folate, and leucovorin (folinic acid) during pralatrexate treatment. Pralatrexate can be a promising treatment with the potential to provide lasting benefit for advanced CTCL patients with the relative low toxicity. Recently, a phase $1 / 2$ study suggested that combination therapy of $150 \mathrm{mg} / \mathrm{m}^{2}$ daily bexarotene plus $15 \mathrm{mg} / \mathrm{m}^{2} /$ week for $3 / 4$ weeks pralatrexate is active with high ORR $(60 \%)$ and minimal toxicity for CTCL (64). A phase 1 study of pralatrexate (10 to $25 \mathrm{mg} / \mathrm{m}^{2}$ ) and romidepsin (12 to $14 \mathrm{mg} / \mathrm{m}^{2}$ ) on 1 of 3 schedules: every week $\times$ 3 every 28 days, every week $\times 2$ every 21 days, and every other week every 28 days, for patients with PTCL also showed high ORR (57\%) (65). These combination therapies with pralatrexate plus bexarotene or romidepsin can be an efficient and tolerated treatment option.

\section{FORODESINE}

Purine nucleoside phosphorylase (PNP) is an important enzyme for the phosphorolysis of purine nucleosides. Severe immunodeficiency syndromes are caused by congenital defects in this enzyme through selective depletion of T cells but not of B cells $(66,67)$. Based on increased nucleoside metabolism of malignant $\mathrm{T}$ cells, $\mathrm{T}$-cell tumor cells can be highly sensitive to the inhibition of PNP (68). Forodesine is a potent inhibitor of PNP that causes apoptosis in both neoplastic T cells and normal $\mathrm{T}$ cells.

In a multicenter phase 2 open-label study, 144 patients with MF/SS who had been treated with three or more systemic therapies were enrolled. The patients received oral forodesine $200 \mathrm{mg}$ daily. The drug showed limited clinical activity in this study. No CRs were observed, and only $11 \%$ of the patients achieved PR and 50\% maintained SD. The median DOR was 191 days (25). Although almost all patients (96\%) experienced at least one $\mathrm{AE}$, most AEs were grade 1/2. Common AEs were peripheral edema, fatigue, insomnia, pruritus, diarrhea, headache, and nausea.

Forodesine was approved in Japan for the treatment of PTCL at the dose of $600 \mathrm{mg}$ daily based on efficacy and safety results of the phase $1 / 2$ clinical trial in patients with 48 relapsed PTCL including one transformed MF patient (65). In 41 evaluable patients, the ORR was $25 \%$ including 4 CRs. The most common grade 3/4 AEs were lymphopenia (96\%), leukopenia (42\%), and neutropenia (35\%). Dose reduction and discontinuation due to AEs were uncommon. There is a possibility that such high-dose can be an effective and acceptable treatment for advanced MF/SS. 


\section{DENILEUKIN DIFTITOX}

Denileukin diftitox is a genetically engineered fusion protein combining the full-length sequence of human IL-2 with the cytotoxic and membrane-translocating domains of the diphtheria toxin. After binding to the IL-2 receptor (IL-2R) on neoplastic $\mathrm{T}$ cells, the drug is internalized. The diphtheria toxin results in the production of a single polypeptide chain that is capable of inhibiting protein synthesis in the cells, leading to cell death (69). The human IL-2R consisted of three forms: low, intermediate, and high affinity. The high affinity IL-2R is a complex of distinct proteins of $\alpha$ chain (CD25), $\beta$ chain (CD122), and $\gamma$ chain (CD132). The intermediate one is composed of CD122 and CD132, and CD25 alone defines the low affinity one. Although denileukin diftitox can bind to all forms of the IL-2R, internalization is caused by only intermediate or high affinity receptors (70). In addition, it is known that the baseline expression level of CD25, which is not included in the intermediate affinity IL-2R, on CTCL cell in lesional skin correlated with their clinical response to denileukin diftitox (71), suggesting that the high affinity IL-2R is the most important receptor to elicit an effect.

The largest study of denileukin diftitox was a multicenter, randomized, double-blind placebo-controlled phase 3 trial that evaluated denileukin diftitox ( 9 or $18 \mu \mathrm{g} / \mathrm{kg} /$ day) vs. placebo in 144 stage IA-III MF/SS patients who had been treated with at most three prior therapies (26). The trial excluded patients with low CD25 expression disease (defined as detectable CD25 on $<20 \%$ of $\mathrm{T}$ cells in lesional skin). The drugs were administered for consequent 5 days every 3 weeks for up to eight cycles. The ORR for the denileukin diftitox $18 \mu \mathrm{g} / \mathrm{kg} /$ day group was $49.1 \%$ with $9.1 \% \mathrm{CR}(n=55)$, compared with $15.9 \%$ with

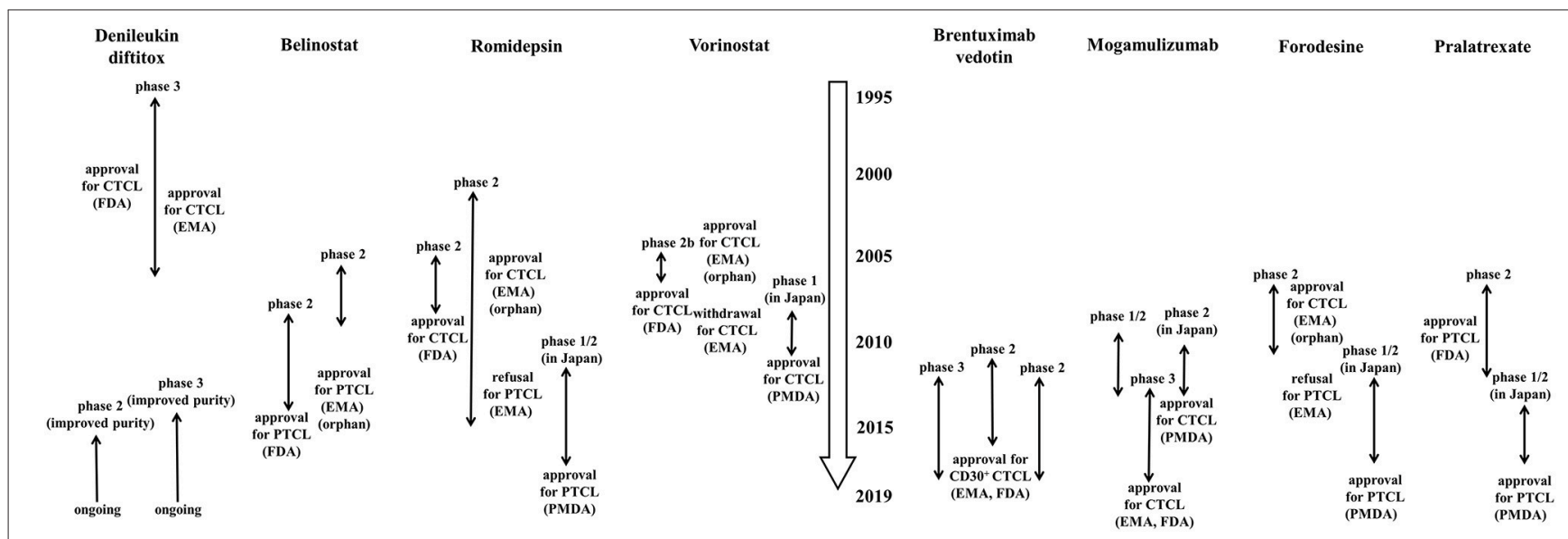

FIGURE 1 | History of clinical trials of single-agents which have been approved for cutaneous T-cell lymphoma or peripheral T-cell lymphoma by FDA, EMA, or PMDA. The data were collected on March 31, 2019. When the drug was approved as orphan drug from EMA, the comment "orphan" is added. CTCL, Cutaneous T-cell lymphoma; PTCL, peripheral T-cell lymphoma; FDA, food and drug administration; EMA, European medicines agency; PMDA, pharmaceuticals and medical devices agency.

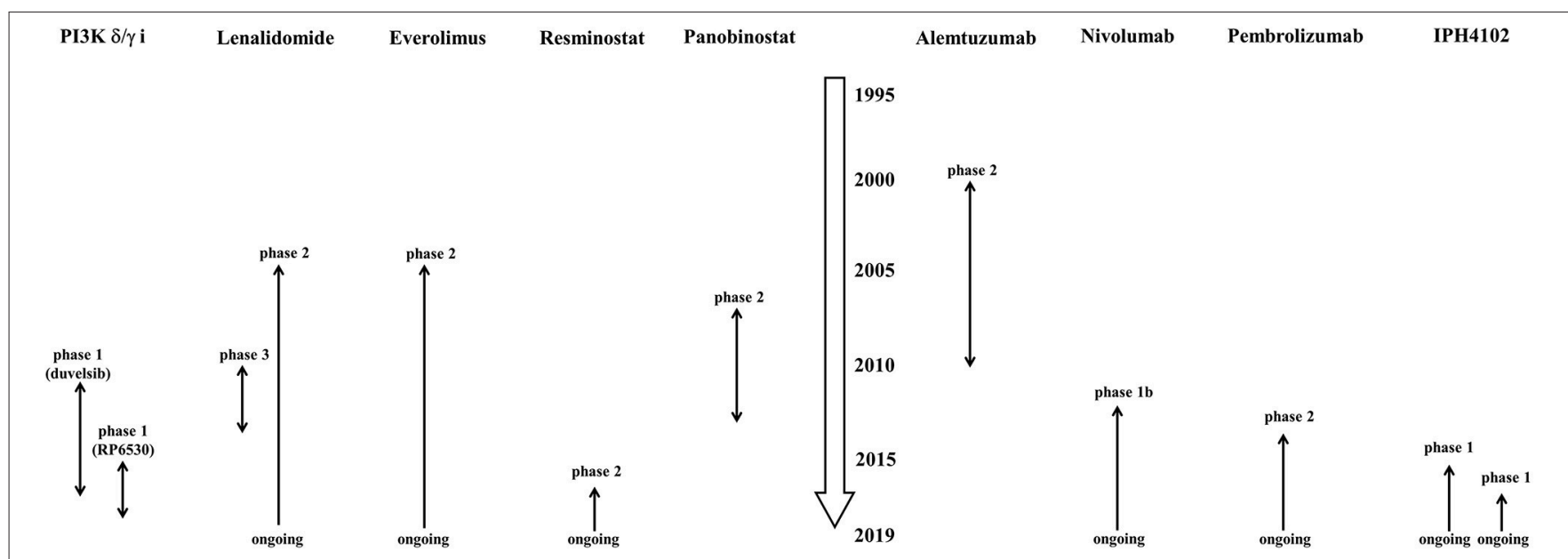

FIGURE 2 | History of clinical trials of single-agents which have not been approved for cutaneous T-cell lymphoma or peripheral T-cell lymphoma by FDA, EMA, or PMDA. The data were collected on March 31, 2019. PI3K $\delta / \gamma$ I, phosphoinositide-3-kinase $\delta / \gamma$ inhibitor. 
$2.3 \% \mathrm{CR}$ for placebo $(n=44)$. For the denileukin diftitox $9 \mu \mathrm{g} / \mathrm{kg} /$ day group, the ORR was $37.8 \%(n=45 ; 11.1 \%$ CR and $26.7 \% \mathrm{PR}$ ). The PFS was significantly prolonged for denileukin diftitox-treated patients compared to patients treated with placebo. Estimated median PFS was at least 971 days for the denileukin diftitox $18 \mu \mathrm{g} / \mathrm{kg}$ /day cohort, 794 days for the denileukin diftitox $9 \mu \mathrm{g} / \mathrm{kg} /$ day cohort, and only 124 days for placebo cohort. The drug-related severe AEs occurred in $25 \%$ of the participants receiving denileukin diftitox with premedication of acetaminophen and antihistamine. The most common drugrelated severe AEs were dehydration (2\%) and capillary leak syndrome (2\%). To assess the denileukin diftitox effect on patients with low CD25 expression, 36 patients with MF/SS who had been excluded from the placebo-controlled trial due to low CD25 expression were enrolled in another clinical trial. In the clinical trial, patients were treated with denileukin diftitox 18 $\mu \mathrm{g} / \mathrm{kg} /$ day for 5 consecutive days every 3 weeks for up to eight courses. The ORR was $30.6 \%$ (8.3\% CR and 22.2\% PR) (72). This study suggests that low CD25 expression does not necessarily preclude a meaningful clinical response to denileukin diftitox in patients with CTCL.

Denileukin diftitox had been approved by the FDA in 1999 for the treatment of patients with CTCL refractory to standard treatment options. However, denileukin diftitox is unavailable on the global market at this time. Currently, the related agent E7777 which shares an amino acid sequence with denileukin diftitox but has improved its purity and an increased percentage of active protein monomer species is being evaluated. A phase 1 study for 13 patients with PTCL conducted in Japan showed that E7777 is well-tolerated and has antitumor activity with $38 \%$ ORR (73). A phase 2 clinical trial of E7777 for relapsed or refractory PTCL and CTCL (NCT02676778) and a phase 3 clinical trial for persistent and recurrent CTCL (NCT01871727) are ongoing.

\section{DUVELISIB}

Phosphoinositide-3-kinase (PI3K) is a lipid kinase involved in intracellular signal transduction and regulates multiple cellular functions relevant to oncogenesis. The PI3K- $\delta$ and PI3K$\gamma$ isoforms, which are preferentially expressed in leukocytes, can modulate both innate and adaptive immune response (74-77). PI3K- $\delta$ and $\mathrm{PI} 3 \mathrm{~K}-\gamma$ mediate multiple pathways contributing to survival, proliferation, and differentiation in malignant hematopoietic cells. Moreover, PI3K signaling is involved in development of tumor microenvironment through juxta-, para-, and endocrine effects on stromal and immune cells (78-80). Additionally, PI3K- $\gamma$ may also suppress antitumor immune response by inhibiting phagocytosis by tumor-associated macrophages (81). Thus, there are at least three different mechanisms via which PI $3 \mathrm{~K}-\delta$ and PI3K- $\gamma$ inhibitors could be effective for hematopoietic malignancies.

Duvelisib (also known as IPI-145) is an oral, dual inhibitor of PI3K- $\delta$ and PI3K- $\gamma$. In a recent phase 1 open-label trial, clinical activity of duvelisib was promising and the toxicity was acceptable in relapsed or refractory PTCL and CTCL (27). Thirtyfive patients (16 PTCL, 19 CTCL) were enrolled in this study and
$27(77 \%)$ were treated at the maximum tolerated of oral duvelisib $75 \mathrm{mg}$ twice daily on a 28-day cycle. The 19 patients with CTCL had received a median of six prior therapies. The CTCL population was composed of 13 patients with MF, five patients with SS, and one primary cutaneous ALCL patient. In the CTCL population, the ORR was $31.6 \%$ (all PR) and the median PFS was 4.5 months. The most common grade $3 / 4$ AEs were increase of liver enzymes (40\%), neutropenia (17\%), maculopapular rash (17\%), and pneumonia (17\%). Thus, this study suggests that duvelisib has clinical activity with an acceptable toxicity, while further studies are needed to determine the optimal dose and identify an appropriate combination therapy. A phase $1 / 1 \mathrm{~b}$ clinical trial of the other dual inhibitor of PI3K- $\delta$ and PI3K- $\gamma$, RP6530, in relapsed and refractory T-cell Lymphoma has been finished, but data analysis is incomplete (NCT02567656).

\section{LENALIDOMIDE}

Lenalidomide, a derivative of thalidomide, is an oral immunomodulatory drug with direct immune-mediated mechanism (82). Lenalidomide has been shown to induce growth arrest and apoptosis in lymphoma cell lines and FDA approved the drug for the treatment of myelodysplastic syndrome, refractory/relapsed multiple myeloma, and mantle cell lymphoma $(83,84)$. In addition, lenalidomide is currently being used in clinical trials to treat other various hematopoietic malignancies.

A multicenter phase 2 study of lenalidomide in 32 patients with MF/SS who progressed following a median of 4 systemic therapies was conducted between 2005 and 2010 (28). The first 19 patients received lenalidomide at a daily dose of $25 \mathrm{mg}$ orally for 21 days of a 28 -day cycle. The remaining 13 patients initiated treatment at a dose of $10 \mathrm{mg}$ daily and the dose was then increased by $5 \mathrm{mg}$ every 28 days to a maximum of $25 \mathrm{mg}$ daily, based on patient safety and response. The ORR was $28 \%$ (all PR) with the median PFS of 8 months. The most frequent AEs were lower leg edema, anemia, fatigue, and transient flare reaction that mimic worsening of the patient's disease. Patients with a 25-mg starting dose showed AEs more frequently than those with a $10-\mathrm{mg}$ starting dose. In a phase 3 randomized study of lenalidomide maintenance vs. observation alone after disease control with other therapies in 21 advanced CTCL patients, the median PFS was 5.3 months in the maintenance lenalidomide group $(n=$ 9) and 2 months in the observation alone group $(n=12)(85)$. Because lenalidomide was used as a maintenance therapy, ORR was not evaluated. The main AEs noted in the lenalidomide arm were neutropenia, erythema multiforme, periorbital edema, hypothyroidism, and pruritus. Although statistical comparison in this study was severely underpowered, lenalidomide may be used as a maintenance therapy after debulking therapy.

\section{EVEROLIMUS}

Everolimus is an oral agent that targets the mammalian target of rapamycin (mTOR) pathway. The mTOR regulates several survival and growth pathways in a variety of cancers, which was 
also shown for T-cell non-Hodgkin lymphoma. In addition, an immunohistochemical study revealed that activation of mTOR pathway in MF is associated with the acquisition of a more aggressive phenotype (86). In the recent phase 2 clinical trial, 16 patients with relapsed or refractory T-cell lymphoma including 7 patients with MF were enrolled and received oral everolimus $10 \mathrm{mg}$ daily. The ORR was $44 \%$ and the median PFS was 4.1 months (29). Regarding MF, three of seven patients showed PR and none reached CR. The most frequent AEs were hematologic toxicity and skin rash.

\section{CONCLUSION}

Although many patients with early CTCL have slow-progressing disease with a normal life expectancy, prognosis of patients with advanced stages of CTCL is poor. Generally speaking, CTCL is incurable without allogeneic stem cell transplantation. Current treatment outcome is characterized by high relapse rates and low durable remission rates. As treatment of advancedstage CTCL is mostly palliative and not curable, a stage-based approach utilizing sequential therapies in an escalated manner is currently favorable. Existing clinical practice guidelines

\section{REFERENCES}

1. Willemze R. Cutaneous T-cell lymphoma: epidemiology, etiology, and classification. Leuk Lymphoma. (2003) 44 (Suppl. 3): S49-54. doi: 10.1080/10428190310001623766

2. Trautinger F, Eder J, Assaf C, Bagot M, Cozzio A, Dummer R, et al. European Organisation for Research and Treatment of Cancer consensus recommendations for the treatment of mycosis fungoides/Sézary syndrome - Update 2017. Eur J Cancer. (2017) 77:57-74. doi: 10.1016/j.ejca.2017.02.027

3. Agar NS, Wedgeworth E, Crichton S, Mitchell TJ, Cox M, Ferreira $\mathrm{S}$, et al. Survival outcomes and prognostic factors in mycosis fungoides/sézary syndrome: validation of the revised international society for Cutaneous Lymphomas/European Organisation for research and treatment of cancer staging proposal. J Clin Oncol. (2010) 28:4730-9. doi: 10.1200/JCO.2009.27.7665

4. Leuchte K, Schlaak M, Stadler R, Theurich S, von Bergwelt-Baildon M. Innovative treatment concepts for cutaneous T-cell lymphoma based on microenvironment modulation. Oncol Res Treat. (2017) 40:262-9. doi: $10.1159 / 000472257$

5. Virmani P, Zain J, Rosen ST, Myskowski PL, Querfeld C. Hematopoietic stem cell transplant for Mycosis fungoides and sézary syndrome. Dermatol Clin. (2015) 33:807-18. doi: 10.1016/j.det.2015.05.014

6. Ogura M, Ishida $\mathrm{T}$, Hatake $\mathrm{K}$, Taniwaki $\mathrm{M}$, Ando $\mathrm{K}$, Tobinai $\mathrm{K}$, et al. Multicenter Phase II Study of Mogamulizumab (KW-0761), a Defucosylated Anti-CC Chemokine Receptor 4 Antibody, in Patients With Relapsed Peripheral T-Cell Lymphoma and Cutaneous T-Cell Lymphoma. J Clin Oncol. (2014) 32:1157-63. doi: 10.1200/JCO.2013.52.0924

7. Duvic M, Pinter-Brown LC, Foss FM, Sokol L, Jorgensen JL, Challagundla P, et al. Phase $1 / 2$ study of mogamulizumab, a defucosylated anti-CCR4 antibody, in previously treated patients with cutaneous T-cell lymphoma. Blood. (2015) 125:1883-9. doi: 10.1182/blood-2014-09-600924

8. Kim YH, Bagot M, Pinter-Brown L, Rook AH, Porcu P, Horwitz $\mathrm{SM}$, et al. Mogamulizumab versus vorinostat in previously treated cutaneous T-cell lymphoma (MAVORIC): an international, open-label, randomised, controlled phase 3 trial. Lancet Oncol. (2018) 19:1192-204. doi: 10.1016/S1470-2045(18)30379-6

9. Kim YH, Tavallaee M, Sundram U, Salva KA, Wood GS, Li S, et al. Phase II investigator-initiated study of brentuximab vedotin in mycosis are quite heterogeneous. Consequently, therapeutic decisions should be individualized to each patient by means of a riskproportionate approach. Although many novel therapeutic agents have been developed and clinical trials for CTCL and PTCL had or have been implemented (Figures 1, 2), such drugs also showed limited efficacy as reviewed in this paper. Thus, it is necessary to know which therapy is preferable for each patient with MF/SS. Creatively designed international clinical trials, such as MAVORIC study and ALCANZA study, should be encouraged.

\section{AUTHOR CONTRIBUTIONS}

TO conceived the concept and wrote the manuscript. TM co-conceived the concept, edited and improved the manuscript, and drafted the table.

\section{FUNDING}

This work was supported by the grant from the Ministry of Education, Culture, Sports, Science, and Technology in Japan (16K19709). fungoides and sézary syndrome with variable $\mathrm{CD} 30$ expression level: a multi-institution collaborative project. J Clin Oncol. (2015) 33:3750-8. doi: 10.1200/JCO.2014.60.3969

10. Duvic M, Tetzlaff MT, Gangar P, Clos AL, Sui D, Talpur R. Results of a phase II trial of brentuximab vedotin for $\mathrm{CD} 30+$ cutaneous $\mathrm{t}$-cell lymphoma and lymphomatoid papulosis. J Clin Oncol. (2015) 33:3759-65. doi: 10.1200/JCO.2014.60.3787

11. Prince HM, Kim YH, Horwitz SM, Dummer R, Scarisbrick J, Quaglino $\mathrm{P}$, et al. Brentuximab vedotin or physician's choice in CD30-positive cutaneous T-cell lymphoma (ALCANZA): an international, openlabel, randomised, phase 3, multicentre trial. Lancet. (2017) 390:555-66. doi: 10.1016/S0140-6736(17)31266-7

12. Lundin J, Hagberg H, Repp R, Cavallin-Ståhl E, Fredén S, Juliusson G, et al. Phase 2 study of alemtuzumab (anti-CD52 monoclonal antibody) in patients with advanced mycosis fungoides/Sezary syndrome. Blood. (2003) 101:4267-72. doi: 10.1182/blood-2002-09-2802

13. Lesokhin AM, Ansell SM, Armand P, Scott EC, Halwani A, Gutierrez M, et al. Nivolumab in patients with relapsed or refractory hematologic malignancy: preliminary results of a phase Ib study. J Clin Oncol. (2016) 34:2698-704. doi: 10.1200/JCO.2015.65.9789

14. Khodadoust M, Rook AH, Porcu P, Foss FM, Moskowitz AJ, Shustov AR, et al. Pembrolizumab for treatment of relapsed/refractory mycosis fungoides and sezary syndrome: clinical efficacy in a citn multicenter phase 2 study. Blood. (2016) 128:181.

15. Bagot M, Porcu P, Ram-Wolff C, Khodadoust M, Basem W, Battistella M, et al. IPH4102, the first-in-class anti- KIR3DL2 mAb, is safe and clinically active in advanced cutaneous T-cell lymphoma (CTCL) patients: results from the doseescalation part of the IPH4102-101 phase I study. In: European Organisation for Research and Treatment of Cancer: Cutaneous Lymphoma Task Force. John Wiley \& Sons, Ltd (2017).

16. Bagot M, Porcu P, Basem W, Battistella M, Vermeer M, Whittaker S, et al. IPH4102; an Anti-KIR3DL2 monoclonal antibody in refractory sezary syndrome: results from a multicenter phase 1 trial. In: American Society of Hematology. John Wiley \& Sons, Ltd; 2018. doi: 10.1002/hon.2437_31

17. Olsen EA, Kim YH, Kuzel TM, Pacheco TR, Foss FM, Parker S, et al. Phase IIb multicenter trial of vorinostat in patients with persistent, progressive, or treatment refractory cutaneous T-cell lymphoma. J Clin Oncol. (2007) 25:3109-15. doi: 10.1200/JCO.2006.10.2434 
18. Duvic M, Talpur R, Ni X, Zhang C, Hazarika P, Kelly C, et al. Phase 2 trial of oral vorinostat (suberoylanilide hydroxamic acid, SAHA) for refractory cutaneous T-cell lymphoma (CTCL). Blood. (2007) 109:31-9. doi: 10.1182/blood-2006-06-025999

19. Piekarz RL, Frye R, Turner M, Wright JJ, Allen SL, Kirschbaum MH, et al. Phase II multi-institutional trial of the histone deacetylase inhibitor romidepsin as monotherapy for patients with cutaneous T-cell lymphoma. $J$ Clin Oncol. (2009) 27:5410-7. doi: 10.1200/JCO.2008.21.6150

20. Whittaker SJ, Demierre M-F, Kim EJ, Rook AH, Lerner A, Duvic M, et al. Final results from a multicenter, international, pivotal study of romidepsin in refractory cutaneous T-cell lymphoma. J Clin Oncol. (2010) 28:4485-91. doi: 10.1200/JCO.2010.28.9066

21. Duvic M, Dummer R, Becker JC, Poulalhon N, Ortiz Romero P, Grazia Bernengo M, et al. Panobinostat activity in both bexarotene-exposed and naïve patients with refractory cutaneous T-cell lymphoma: Results of a phase II trial. Eur J Cancer. (2013) 49:386-94. doi: 10.1016/J.EJCA.2012.08.017

22. Foss F, Advani R, Duvic M, Hymes KB, Intragumtornchai T, Lekhakula A, et al. A Phase II trial of Belinostat (PXD101) in patients with relapsed or refractory peripheral or cutaneous T-cell lymphoma. Br J Haematol. (2015) 168:811-9. doi: $10.1111 /$ bjh. 13222

23. Robert C, Ribas A, Wolchok JD, Hodi FS, Hamid O, Kefford R, et al. Anti-programmed-death-receptor-1 treatment with pembrolizumab in ipilimumab-refractory advanced melanoma: a randomised dosecomparison cohort of a phase 1 trial. Lancet. (2014) 384:1109-17. doi: 10.1016/S0140-6736(14)60958-2

24. Foss F, Horwitz SM, Coiffier B, Bartlett N, Popplewell L, Pro B, et al. Pralatrexate is an effective treatment for relapsed or refractory transformed mycosis fungoides: a subgroup efficacy analysis from the PROPEL study. Clin Lymphoma Myeloma Leuk. (2012) 12:238-43. doi: 10.1016/j.clml.2012.01.010

25. Dummer R, Duvic M, Scarisbrick J, Olsen EA, Rozati S, Eggmann $\mathrm{N}$, et al. Final results of a multicenter phase II study of the purine nucleoside phosphorylase (PNP) inhibitor forodesine in patients with advanced cutaneous t-cell lymphomas (CTCL) (Mycosis fungoides and Sezary syndrome). Ann Oncol. (2014) 25:1807-12. doi: 10.1093/annonc/mdu231

26. Prince HM, Duvic M, Martin A, Sterry W, Assaf C, Sun Y, et al. Phase III placebo-controlled trial of denileukin diftitox for patients with cutaneous T-cell lymphoma. J Clin Oncol. (2010) 28:1870-7. doi: 10.1200/JCO.2009.26.2386

27. Horwitz SM, Koch R, Porcu P, Oki Y, Moskowitz A, Perez M, et al. Activity of the $\mathrm{PI} 3 \mathrm{~K}-\delta, \gamma$ inhibitor duvelisib in a phase 1 trial and preclinical models of T-cell lymphoma. Blood. (2018) 131:888-98. doi: 10.1182/blood-2017-08-802470

28. Querfeld C, Rosen ST, Guitart J, Duvic M, Kim YH, Dusza SW, et al. Results of an open-label multicenter phase 2 trial of lenalidomide monotherapy in refractory mycosis fungoides and Sézary syndrome. Blood. (2014) 123:115966. doi: 10.1182/blood-2013-09-525915

29. Witzig TE, Reeder C, Han JJ, LaPlant B, Stenson M, Tun HW, et al. The mTORC1 inhibitor everolimus has antitumor activity in vitro and produces tumor responses in patients with relapsed T-cell lymphoma. Blood. (2015) 126:328-35. doi: 10.1182/blood-2015-02-629543

30. Ferenczi K, Fuhlbrigge RC, Kupper TS, Pinkus JL, Pinkus GS. Increased CCR4 Expression in Cutaneous T Cell Lymphoma. J Invest Dermatol. (2002) 119:1405-10. doi: 10.1046/J.1523-1747.2002.19610.X

31. Ishida $\mathrm{T}$, Inagaki $\mathrm{H}$, Utsunomiya A, Takatsuka $\mathrm{Y}$, Komatsu $\mathrm{H}$, Iida S, et al. CXC chemokine receptor 3 and CC chemokine receptor 4 expression in Tcell and NK-cell lymphomas with special reference to clinicopathological significance for peripheral T-cell lymphoma, unspecified. Clin Cancer Res. (2004) 10:5494-500. doi: 10.1158/1078-0432.CCR-04-0371

32. Ishida $T$, Utsunomiya A, Iida S, Inagaki H, Takatsuka Y, Kusumoto S, et al. Clinical significance of CCR4 expression in adult T-cell leukemia/lymphoma: its close association with skin involvement and unfavorable outcome. Clin Cancer Res. (2003) 9:3625-34.

33. Yoshie O, Fujisawa R, Nakayama T, Harasawa $H$, Tago $H$, Izawa $D$, et al. Frequent expression of CCR4 in adult T-cell leukemia and human Tcell leukemia virus type 1-transformed T cells. Blood. (2002) 99:1505-11. doi: 10.1182/blood.V99.5.1505

34. Ishii $\mathrm{T}$, Ishida $\mathrm{T}$, Utsunomiya $\mathrm{A}$, Inagaki $\mathrm{A}$, Yano $\mathrm{H}$, Komatsu $\mathrm{H}$, et al. Defucosylated humanized anti-CCR4 monoclonal antibody KW-0761 as a novel immunotherapeutic agent for adult T-cell leukemia/lymphoma. Clin Cancer Res. (2010) 16:1520-31. doi: 10.1158/1078-0432.CCR-09-2697

35. Ishida T, Jo T, Takemoto S, Suzushima H, Uozumi K, Yamamoto K, et al. Doseintensified chemotherapy alone or in combination with mogamulizumab in newly diagnosed aggressive adult T-cell leukaemia-lymphoma: a randomized phase II study. Br J Haematol. (2015) 169:672-82. doi: 10.1111/bjh.13338

36. van de Donk NWCJ, Dhimolea E. Brentuximab vedotin. MAbs. (2012) 4:458 65. doi: $10.4161 /$ mabs. 20230

37. Deng C, Pan B, O’Connor OA. Brentuximab vedotin. Clin Cancer Res. (2013) 19:22-7. doi: 10.1158/1078-0432.CCR-12-0290

38. Pro B, Advani R, Brice P, Bartlett NL, Rosenblatt JD, Illidge T, et al Brentuximab vedotin (SGN-35) in patients with relapsed or refractory systemic anaplastic large-cell lymphoma: results of a phase II study. J Clin Oncol. (2012) 30:2190-6. doi: 10.1200/JCO.2011.38.0402

39. Bernengo MG, Quaglino P, Comessatti A, Ortoncelli M, Novelli M, Lisa F, et al. Low-dose intermittent alemtuzumab in the treatment of Sézary syndrome: clinical and immunologic findings in 14 patients. Haematologica. (2007) 92:784-94. doi: 10.3324/haematol.11127

40. Watanabe R, Teague JE, Fisher DC, Kupper TS, Clark RA. Alemtuzumab therapy for leukemic cutaneous T-cell lymphoma. JAMA Dermatol. (2014) 150:776. doi: 10.1001/jamadermatol.2013.10099

41. Wolchok JD, Kluger H, Callahan MK, Postow MA, Rizvi NA, Lesokhin AM, et al. Nivolumab plus ipilimumab in advanced melanoma. $N$ Engl J Med. (2013) 369:122-33. doi: 10.1056/NEJMoa1302369

42. Brahmer JR, Tykodi SS, Chow LQM, Hwu W-J, Topalian SL, Hwu P, et al. Safety and activity of anti-PD-L1 antibody in patients with advanced cancer. N Engl J Med. (2012) 366:2455-65. doi: 10.1056/NEJMoa1200694

43. Topalian SL, Hodi FS, Brahmer JR, Gettinger SN, Smith DC, McDermott DF, et al. Safety, activity, and immune correlates of anti-PD-1 antibody in cancer. N Engl J Med. (2012) 366:2443-54. doi: 10.1056/NEJMoa1200690

44. Eggermont AMM, Chiarion-Sileni V, Grob J-J, Dummer R, Wolchok JD, Schmidt $\mathrm{H}$, et al. Prolonged survival in stage III melanoma with ipilimumab adjuvant therapy. $N$ Engl J Med. (2016) 375:1845-55. doi: 10.1056/NEJMoa1611299

45. Ansell SM, Lesokhin AM, Borrello I, Halwani A, Scott EC, Gutierrez M, et al. PD-1 Blockade with nivolumab in relapsed or refractory hodgkin's lymphoma. N Engl J Med. (2015) 372:311-9. doi: 10.1056/NEJMoa1411087

46. Kantekure K, Yang Y, Raghunath P, Schaffer A, Woetmann A, Zhang $\mathrm{Q}$, et al. Expression patterns of the immunosuppressive proteins PD1/CD279 and PD-L1/CD274 at different stages of cutaneous T-cell lymphoma/mycosis fungoides. Am J Dermatopathol. (2012) 34:126-8. doi: 10.1097/DAD.0b013e31821c35cb

47. Samimi S, Benoit B, Evans K, Wherry EJ, Showe L, Wysocka M, et al. Increased Programmed Death-1 expression on CD4+ T cells in cutaneous T-cell lymphoma. Arch Dermatol. (2010) 146:1382. doi: 10.1001/archdermatol.2010.200

48. Herbst RS, Baas P, Kim D-W, Felip E, Pérez-Gracia JL, Han J$\mathrm{Y}$, et al. Pembrolizumab versus docetaxel for previously treated, PD-L1-positive, advanced non-small-cell lung cancer (KEYNOTE010): a randomised controlled trial. Lancet. (2016) 387:1540-50. doi: 10.1016/S0140-6736(15)01281-7

49. Bagot M, Moretta A, Sivori S, Biassoni R, Cantoni C, Bottino C, et al. CD4 $(+)$ cutaneous T-cell lymphoma cells express the p140-killer cell immunoglobulinlike receptor. Blood. (2001) 97:1388-91. doi: 10.1182/blood.V97.5.1388

50. Wechsler J, Bagot M, Nikolova M, Parolini S, Martin-Garcia N, Boumsell $\mathrm{L}$, et al. Killer cell immunoglobulin-like receptor expression delineates in situ Sézary syndrome lymphocytes. J Pathol. (2003) 199:77-83. doi: $10.1002 /$ path. 1251

51. Poszepczynska-Guigné E, Schiavon V, D'Incan M, Echchakir H, Musette P, Ortonne N, et al. CD158k/KIR3DL2 is a new phenotypic marker of Sezary cells: relevance for the diagnosis and follow-up of Sezary syndrome. J Invest Dermatol. (2004) 122:820-3. doi: 10.1111/j.0022-202X.2004.22326.x

52. Bahler DW, Hartung L, Hill S, Bowen GM, Vonderheid EC. CD158k/KIR3DL2 is a useful marker for identifying neoplastic T-cells in Sézary syndrome by flow cytometry. Cytometry B Clin Cytom. (2008) 74:156-62. doi: 10.1002/cyto.b.20395

53. Ortonne N, Le Gouvello S, Tabak R, Marie-Cardine A, Setiao J, Berrehar $\mathrm{F}$, et al. CD158k/KIR3DL2 and NKp46 are frequently expressed 
in transformed mycosis fungoides. Exp Dermatol. (2012) 21:461-3. doi: $10.1111 / j .1600-0625.2012 .01489 . x$

54. Moins-Teisserenc H, Daubord M, Clave E, Douay C, Félix J, Marie-Cardine A, et al. CD158k is a reliable marker for diagnosis of Sézary syndrome and reveals an unprecedented heterogeneity of circulating malignant cells. J Invest Dermatol. (2015) 135:247-57. doi: 10.1038/jid.2014.356

55. Marie-Cardine A, Viaud N, Thonnart N, Joly R, Chanteux S, Gauthier L, et al. IPH4102, a Humanized KIR3DL2 antibody with potent activity against cutaneous T-cell lymphoma. Cancer Res. (2014) 74:6060-70. doi: 10.1158/0008-5472.CAN-14-1456

56. Chun P. Histone deacetylase inhibitors in hematological malignancies and solid tumors. Arch Pharm Res. (2015) 38:933-49. doi: 10.1007/s12272-015-0571-1

57. Lopez AT, Bates S, Geskin L. Current Status of HDAC Inhibitors in Cutaneous T-cell Lymphoma. Am J Clin Dermatol. (2018) 19:805-19. doi: 10.1007/s40257-018-0380-7

58. Wada H, Tsuboi R, Kato Y, Sugaya M, Tobinai K, Hamada T, et al. Phase I and pharmacokinetic study of the oral histone deacetylase inhibitor vorinostat in Japanese patients with relapsed or refractory cutaneous T-cell lymphoma. $J$ Dermatol. (2012) 39:823-8. doi: 10.1111/j.1346-8138.2012.01554.x

59. Foss F, Duvic M, Lerner A, Waksman J, Whittaker S. Clinical efficacy of romidepsin in tumor stage and folliculotropic mycosis fungoides. Clin Lymphoma Myeloma Leuk. (2016) 16:637-43. doi: 10.1016/j.clml.2016. 08.009

60. Kim YH, Demierre M-F, Kim EJ, Lerner A, Rook AH, Duvic M, et al. Clinically meaningful reduction in pruritus in patients with cutaneous Tcell lymphoma treated with romidepsin. Leuk Lymphoma. (2013) 54:284-9. doi: 10.3109/10428194.2012.711829

61. O'Connor OA, Pro B, Pinter-Brown L, Bartlett N, Popplewell L, Coiffier B, et al. Pralatrexate in patients with relapsed or refractory peripheral T-cell lymphoma: results from the pivotal PROPEL study. J Clin Oncol. (2011) 29:1182-9. doi: 10.1200/JCO.2010.29.9024

62. Maruyama D, Nagai H, Maeda Y, Nakane T, Shimoyama T, Nakazato T, et al. Phase I/II study of pralatrexate in Japanese patients with relapsed or refractory peripheral T-cell lymphoma. Cancer Sci. (2017) 108:2061-8. doi: $10.1111 /$ cas. 13340

63. Horwitz SM, Kim YH, Foss F, Zain JM, Myskowski PL, Lechowicz MJ, et al. Identification of an active, well-tolerated dose of pralatrexate in patients with relapsed or refractory cutaneous T-cell lymphoma. Blood. (2012) 119:4115-22. doi: 10.1182/blood-2011-11-390211

64. Duvic M, Kim YH, Zinzani PL, Horwitz SM. Results from a Phase I/II open-label, dose-finding study of pralatrexate and oral bexarotene in patients with relapsed/refractory cutaneous T-cell lymphoma. Clin Cancer Res. (2017) 23:3552-6. doi: 10.1158/1078-0432.CCR-16-2064

65. Amengual JE, Lichtenstein R, Lue J, Sawas A, Deng C, Lichtenstein E, et al. A phase 1 study of romidepsin and pralatrexate reveals marked activity in relapsed and refractory T-cell lymphoma. Blood. (2018) 131:397-407. doi: 10.1182/blood-2017-09-806737

66. Bantia S, Ananth SL, Parker CD, Horn LL, Upshaw R. Mechanism of inhibition of T-acute lymphoblastic leukemia cells by PNP inhibitor-BCX-1777. Int Immunopharmacol. (2003) 3:879-87. doi: $10.1016 /$ S1567-5769(03)00076-6

67. Markert ML. Purine nucleoside phosphorylase deficiency. Immunodefic Rev. (1991) 3:45-81.

68. Gandhi V, Kilpatrick JM, Plunkett W, Ayres M, Harman L, Du M, et al. A proof-of-principle pharmacokinetic, pharmacodynamic, and clinical study with purine nucleoside phosphorylase inhibitor immucillin-H (BCX-1777, forodesine). Blood. (2005) 106:4253-60. doi: 10.1182/blood-2005-03-1309

69. Bacha P, Williams DP, Waters C, Williams JM, Murphy JR, Strom TB. Interleukin 2 receptor-targeted cytotoxicity. Interleukin 2 receptor-mediated action of a diphtheria toxin-related interleukin 2 fusion protein. J Exp Med. (1988) 167:612-22.

70. Waters CA, Schimke PA, Snider CE, Itoh K, Smith KA, Nichols JC, et al. Interleukin 2 receptor-targeted cytotoxicity. Receptor binding requirements for entry of a diphtheria toxin-related interleukin 2 fusion protein into cells. Eur J Immunol. (1990) 20:785-91. doi: 10.1002/eji.1830200412
71. Talpur R, Jones DM, Alencar AJ, Apisarnthanarax N, Herne KL, Yang Y, et al. CD25 expression is correlated with histological grade and response to denileukin diftitox in cutaneous T-cell lymphoma. J Invest Dermatol. (2006) 126:575-83. doi: 10.1038/sj.jid.5700122

72. Prince HM, Martin AG, Olsen EA, Fivenson DP, Duvic M. Denileukin diftitox for the treatment of CD25 low-expression mycosis fungoides and Sézary syndrome. Leuk Lymphoma. (2013) 54:69-75. doi: 10.3109/10428194.2012.706286

73. Ohmachi K, Ando K, Ogura M, Uchida T, Tobinai K, Maruyama D, et al. E7777 in Japanese patients with relapsed/refractory peripheral and cutaneous T-cell lymphoma: a phase I study. Cancer Sci. (2018) 109:794-802. doi: $10.1111 /$ cas. 13513

74. Clayton E, Bardi G, Bell SE, Chantry D, Downes CP, Gray A, et al. A crucial role for the p110delta subunit of phosphatidylinositol 3-kinase in B cell development and activation. J Exp Med. (2002) 196:753-63. doi: $10.1084 /$ jem. 20020805

75. Okkenhaug K, Bilancio A, Farjot G, Priddle H, Sancho S, Peskett E, et al. Impaired $\mathrm{B}$ and $\mathrm{T}$ cell antigen receptor signaling in p110delta PI 3-kinase mutant mice. Science. (2002) 297:1031-4. doi: 10.1126/science.1073560

76. Vanhaesebroeck B, Guillermet-Guibert J, Graupera M, Bilanges B. The emerging mechanisms of isoform-specific PI3K signalling. Nat Rev Mol Cell Biol. (2010) 11:329-41. doi: 10.1038/nrm2882

77. Fung-Leung W-P. Phosphoinositide 3-kinase delta (PI3K $\delta$ ) in leukocyte signaling and function. Cell Signal. (2011) 23:603-8. doi: 10.1016/j.cellsig.2010.10.002

78. Lewis CE, Pollard JW. Distinct role of macrophages in different tumor microenvironments. Cancer Res. (2006) 66:605-12. doi: 10.1158/0008-5472.CAN-05-4005

79. Hanahan D, Weinberg RA. Hallmarks of cancer: the next generation. Cell. (2011) 144:646-74. doi: 10.1016/j.cell.2011.02.013

80. Schmid MC, Avraamides CJ, Dippold HC, Franco I, Foubert P, Ellies LG, et al. Receptor tyrosine kinases and TLR/IL1Rs unexpectedly activate myeloid cell PI3K $\gamma$, a single convergent point promoting tumor inflammation and progression. Cancer Cell. (2011) 19:715-27. doi: 10.1016/j.ccr.2011.04.016

81. Kaneda MM, Messer KS, Ralainirina N, Li H, Leem CJ, Gorjestani S, et al. PI $3 \mathrm{~K} \gamma$ is a molecular switch that controls immune suppression. Nature. (2016) 539:437-42. doi: 10.1038/nature19834

82. Gribben JG, Fowler N, Morschhauser F. Mechanisms of Action of Lenalidomide in B-Cell Non-Hodgkin Lymphoma. J Clin Oncol. (2015) 33:2803-11. doi: 10.1200/JCO.2014.59.5363

83. List A, Kurtin S, Roe DJ, Buresh A, Mahadevan D, Fuchs D, et al. Efficacy of lenalidomide in myelodysplastic syndromes. N Engl J Med. (2005) 352:549-57. doi: 10.1056/NEJMoa041668

84. Yang B, Yu R, Chi X, Lu X. Lenalidomide Treatment for multiple myeloma: systematic review and meta-analysis of randomized controlled trials. PLoS ONE. (2013) 8:e64354. doi: 10.1371/journal.pone.0064354

85. Bagot M, Hasan B, Whittaker S, Beylot-Barry M, Knobler R, Shah E, et al. A phase III study of lenalidomide maintenance after debulking therapy in patients with advanced cutaneous T-cell lymphoma - EORTC 21081 (NCT01098656): results and lessons learned for future trial designs. Eur J Dermatol. (2017) 27:286-94. doi: 10.1684/ejd.2017.3008

86. Levidou G, Siakantaris M, Papadaki T, Papadavid E, Vassilakopoulos TP, Angelopoulou MK, et al. A comprehensive immunohistochemical approach of AKT/mTOR pathway and p-STAT3 in mycosis fungoides. $J$ Am Acad Dermatol. (2013) 69:375-84. doi: 10.1016/J.JAAD.2013.04.027

Conflict of Interest Statement: The authors declare that the research was conducted in the absence of any commercial or financial relationships that could be construed as a potential conflict of interest.

Copyright $\odot 2019$ Oka and Miyagaki. This is an open-access article distributed under the terms of the Creative Commons Attribution License (CC BY). The use, distribution or reproduction in other forums is permitted, provided the original author(s) and the copyright owner(s) are credited and that the original publication in this journal is cited, in accordance with accepted academic practice. No use, distribution or reproduction is permitted which does not comply with these terms. 